\title{
Embracing the Power of Belongingness: A Descriptive Mixed Method Research Study
}

\author{
Kylie Russell*, Selma Alliex, Heather Gluyas \\ School of Nursing and Midwifery, The University of Notre Dame Australia, Fremantle, Australia \\ Email: ${ }^{*}$ kylie.russell@nd.edu.au
}

Received 18 May 2016; accepted 6 June 2016; published 9 June 2016

Copyright (C) 2016 by authors and Scientific Research Publishing Inc.

This work is licensed under the Creative Commons Attribution International License (CC BY). http://creativecommons.org/licenses/by/4.0/

(c) (i) Open Access

\begin{abstract}
Background: Clinical placements should provide nursing students with a positive environment for learning in which they develop a framework for future practice. The literature articulates that this is not always the case. The objective of this research was to develop, implement and evaluate a new education seminar for nursing staff-The Art of Clinical Supervision (ACS), designed for nurses to provide a toolbox of strategies to better support students whilst on clinical placement. The ACS was presented in Western Australia, in both metropolitan and regional health services, in both the public and private health sector. This sample consisted of 199 registered nurses working in areas that actively placed nursing students. A mixed method approach incorporated surveys, online reflections and interviews. This article will outline the qualitative phase of this mixed method research. Analysis of the qualitative data determined that participants perceived the seminar as a helpful strategy for improving nursing practice in relation to student supervision. In particular, the concept of belongingness was viewed as an important component to improving attitudes and placement learning, the focus of this article. The implications of belongingness and how this can be promoted is an important concept that nursing leaders, education providers and clinical supervisors need to consider.
\end{abstract}

\section{Keywords}

Clinical Supervision, Nursing Clinical Placements, Nursing Attitudes

\section{Introduction}

This paper describes the findings from the qualitative phase of a mixed method descriptive study investigating the impact of the Art of Clinical Supervision (ACS), a one-day seminar for Registered Nurses, in Western Aus-

${ }^{*}$ Corresponding author. 
tralia 2012-2013. The ACS was designed and implemented as a strategy to improve nurses' knowledge, and attitude toward, student supervision in the clinical setting. The findings from this study described a wide range of themes regarding clinical supervision; however, this paper will focus on the theme of student "belongingness" [1].

\section{Background}

A student clinical placement should provide a safe and welcoming setting. Students need support and guidance to apply gained knowledge of the profession for the development of safe practice. Welcoming students as members of the health care team can assist with their ability to actively contribute and seek opportunities to learn. To effectively link theory to practice and develop competence students rely on supportive clinical supervisors, who exhibit effective teaching behaviors [1]. Clinical supervision for this study was defined as the oversight, direct or indirect, of a student on clinical placement to learn the practice attributes of the profession [2].

The Art of Clinical Supervision (ACS) was developed as an intensive one-day seminar to support nurse's achieving a positive clinical placement learning experience for students. In addition, strategies to promote a supportive and inclusive environment were included; this involved a 90-minute session on the concept of belongingness. Participants were given time to review the literature on belongingness, followed by small and large group discussions to develop belongingness strategies [1]. Research led by Professor Levett-Jones [3]-[6] was utilized as the main source of literature for this session. Levett-Jones outlined the importance of belongingness in its influence on student learning and impact on student placement satisfaction [3]-[6].

\section{Belongingness}

Belongingness has been widely discussed within both sociology and psychology, and only more recently within the profession of nursing. Each with a different perspective about its significance on human behavior and relationships. Each perspective was utilised for the development of the ACS teaching plan to provide a comprehensive view of the concept and its impact at an individual and group level within the nursing team. Despite the differences of perspective, all describe belongingness as an emotion felt at an individual level, giving a sense of safety and emotional attachment to a particular group [7] [8].

Within the field of sociology, belongingness is a relationship with others that can result in acceptance or exclusion [8] [9]. It views belongingness as the integration of likeminded individuals into a group and explores their ability to facilitate social change [7] [8]. In particular who within the group influences change, how they make these changes and the impact on those excluded [9]. This change may be the result of a sense of agreement, or the groups influence rather than the change itself [9], others may engage despite their disagreement due to a sense of allegiance or to prevent exclusion [8].

Viewing belongingness at the individual level occurs within the field of psychology. Psychology assumes that there is an instinctive need for humans to belong. Belongingness affects individual incentive, behavior, reasoning, wellbeing and health. In contrast, opposite to belongingness, is alienation, which can lead to worry, despair, anguish and isolation. In desperation to gain belonging, individuals can be persuaded to adapt behavior to group customs, often to the extent of engaging in damaging activities [10]-[12]. According to the Hierarchy of Human Needs by Maslow [13] an individual will endeavor to achieve group status to meet the underlying desire of physiological needs and safety.

Given the time spent within the workplace, a number of studies have reviewed the impact of belongingness within this environment. These studies highlighted that inclusion and support in the workplace was viewed as a confirmation of group acceptance [10] [11]. It was also noted that individuals were able to adapt their natural behavior to that of the group to ensure acceptance and inclusion, to the point of engaging in detrimental acts. These were seen as a necessity, even if it affected their capacity to accomplish their long-term professional goals [9].

Within nursing, research led by Levett-Jones [3]-[6] explored the nursing clinical supervision relationship and its impact on student learning. This research included students' stories and emotions around the theory of belonging and its consequence on their clinical placement [6]. The research explored the relationship between students and the supervising nurses of their practice, also considering the area's general level of support and approach towards students [3]. The research described the impact of a supportive and welcoming clinical place- 
ment on learning and the development of professional competence [4]. Whilst negative experiences were linked to limitations in learning and on occasions resulted in student compliance with poor nursing practice to diminish the possibility of exclusion [6]. Students were noted to regret their actions, but emphasized that it was seen as "the lesser of two evils" [4] (p. 348). Levett-Jones and Lathlean [4] outlined that students required safety, security and belonging to engage in learning to enable self-concept, learning and competence. The principal influence on a student's ability to achieve these needs was the nurse that supervised their practice [5].

The nursing literature confirms this influence of the clinical supervisor on student learning. In particular the importance for clinical supervisors to have a self-awareness of their role and attitude toward nursing students; given that students' placement perceptions relate to the attitudes of those around them [1] [14]-[18].

\section{Research}

This research aimed to develop, implement and evaluate a new seminar for registered nurses to support them in their supervision of student practice to provide a quality clinical placement. The impact of the ACS was evaluated using a descriptive methodology involving the collection and analysis of quantitative and qualitative data using a triangulation approach of surveys, online reflections and interviews. The aim of this research was to provide a rich source of data that described the ACS participants' knowledge and attitude towards clinical supervision both before and after attending the day [1].

Approval for the study was obtained from the University of Notre Dame, Australia Human Research Ethics Committee. Participants (registered nurses) were recruited through flyers (with attached application form) forwarded to health services in Western Australia, by email and post, that provided student clinical placements, with applications accepted according to date of receipt. Participants were provided with an Information Sheet and Consent was obtained, participants were free to leave the study at any time. All material was handled confidentially [1].

\section{Data Collection and Analysis}

209 participants attended the study day, with 199 meeting the inclusion criteria of currently working as a RN and involved in the supervision of students. Participants included registered nurses employed within both metropolitan Perth and regional Western Australia, across both the private and public health care sector [1].

The qualitative phase of data collection involved the completion of open-ended survey questions both prior to, immediately after, and eight-weeks after attending the ACS, post program online reflections for eight weeks and interviews. The survey consisted predominantly of quantitative questions to determine participant knowledge of clinical supervision both pre and post attendance to the ACS. In addition, the pre survey encompassed questions related to gender, age, years of nursing experience, clinical supervision experience, clinical supervision education and area of employment (public/private and nursing specialty e.g. mental health, surgical, child health nurse etc.). Participants were allocated a survey number to ensure confidentiality, on completion of data collection, participants details were deleted from their assigned number. 199 (100\%) participants completed the pre survey, 198 (99.5\%) immediate post survey and 71 (35.5\%) post eight-week survey, 117 (58\%) emailed reflections were received and $12(6 \%)$ interviews conducted. Consent to interview was sought at the post eight-week survey, with those actively supervising students invited for interview [1].

The demographics of the research participants described a population that reflected the Western Australian nursing cohort. $74.5 \%$ of participants were employed within a metropolitan health service, with $65.3 \%$ working in the public system. $94.5 \%$ of the participants were female with the main age group being 51 - 60 (30.5\%) years of age followed closely by 41 - 50 years (30\%). 51.5\% participants worked within the general acute hospital setting, $22 \%$ in an educator role, $18 \%$ in the community and $8 \%$ in mental health. $70 \%$ of the participants had more then 10 years of experience with a mean of 19 years. Demographics not comparable to the WA nursing population data, but of interest to the study, described that $51 \%$ of participants had no previous clinical supervision education, with only $32 \%$ attending a short in service or study day. $43 \%$ of participant's supervised students every week, 34\% within every month, and $20 \%$ every 2 - 3 months [1].

This qualitative component of the research utilized a thematic analysis approach as defined by Braun and Clarke [18]. It involved the identification, analysis and development of themes. The formation of these themes occurred within a realist framework that reports the findings according to the participant's experiences and the 
meaning that they assign to these. This method of analysis provides the opportunity to describe participant's experiences per their interpretation of the phenomenon. This process involved six stages-data familiarization through reading and rereading of the data, the allocation of initial codes followed by themes, which were then reviewed and refined prior to producing the $\mathrm{PhD}$ thesis. This process considered the research questions to ensure alignment of the study purpose with the final report [1] [19].

\section{Research Findings}

Consistently across all of the data collection methods an emphasis on belongingness was noted. This concept was seen as particularly influential on the outcome of a student's clinical placement experience. Participants articulated that the concept of being welcomed and included seemed so simple, yet its influence on student learning was a motivating force to ensure this practice was nurtured. This was a significant take-home point of the seminar. Participants' comments in the post eight-week surveys, online reflections and interviews all incorporated remarks on, or examples of, belongingness [1]. The impact of belongingness on participants is articulated in Figure 1. Each of these themes will be explored in further detail.

\subsection{Research Findings}

\subsubsection{Awareness of/Effect of Belongingness on Students' Clinical Placements and Learning Experiences}

Participants discussed how belongingness affected the student's ability to achieve competence in the clinical environment. Throughout the ACS seminar, participants discussed belongingness and its association to learning and attaining competence. Further descriptions of belongingness were included in the qualitative surveys, online reflections and interviews. A number of participants shared their definition of belongingness, or simply an acknowledgement of its importance [1] "to be conducive to learning, you've got to feel you belong. You've got to feel you're in a nourishing, nurturing environment" [1] (p. 238). Whilst another participant in their online reflection noted, "First impressions given to the student such as a friendly welcome and a sense that they are a valuable inclusion of the team and not a burden really influences students. This can either encourage learning with increasing independence or promote anxiety with apprehension impeding learning...Belonging can have an impact" [1] (p. 213). Belongingness was identified as a simple concept, yet overlooked or not thought of, as a strategy to assist students with their learning. Participants felt that this was something that they could easily work towards achieving to improve a student’s placement without it requiring any resources or time [1].

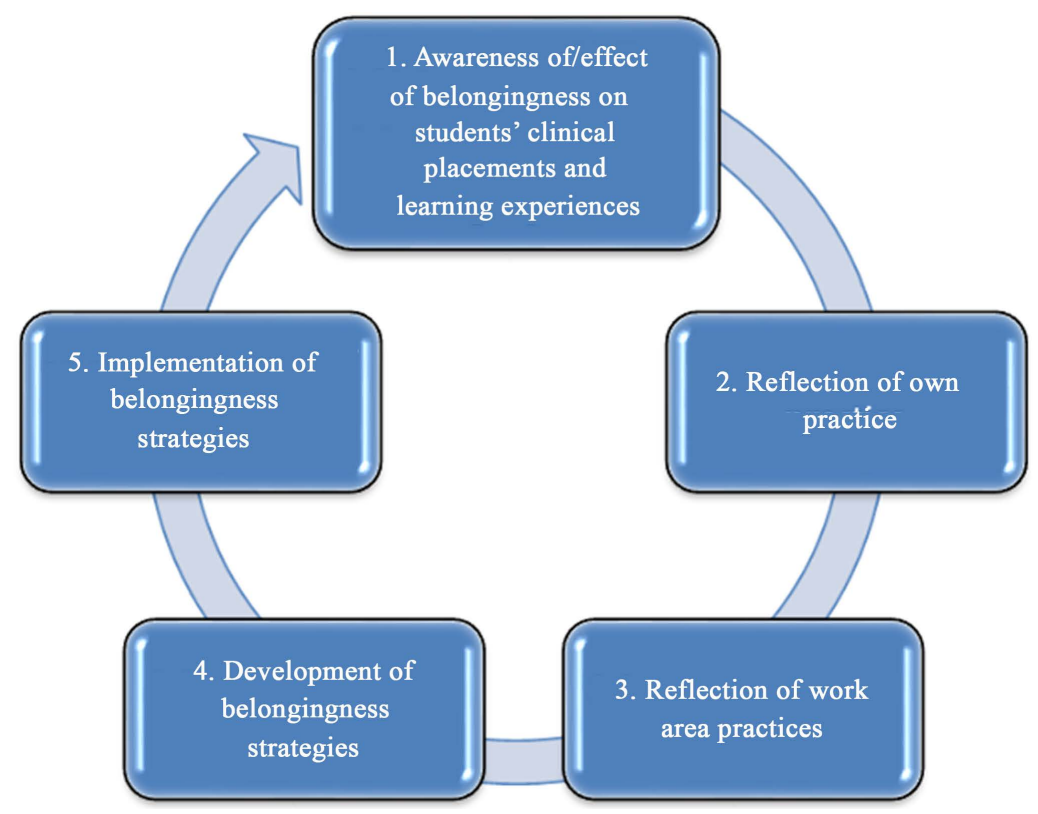

Figure 1. Effect of belongingness on ACS participants [1] (p. 235). 


\subsubsection{Reflection of Own Practice}

The qualitative data described a journey of self-reflection by many of the ACS participants. Participants described how they had reflected on the topic of belonging and on their own interactions with students. For some there was a confirmation of practice that was within a belongingness framework, "continued to give me encouragement to give students a positive experience, ensure they're welcomed, introduced to staff, goals set and learning opportunities provided" [1] (p. 187). Whilst for most participants there was an acknowledgement that their understanding of the role and the actual role requirements taught at the study day were quite different. They simply had not given the role of the clinical supervisor great consideration, and were surprised by the impact that this lack of attention could have. For others a more noted difference in their practice from expectations highlighted that perhaps they had themselves engaged in behavior that was unsupportive, "prior to attending that study day I thought that I was reasonably well skilled... but since attending, it may sound a little corny, but I have had some revelations" [1] (p. 223). Many of the participants referred to their own experiences as a student, and identified how this sense of belonging had shaped them in their development and career choices, whilst acknowledging that they had not connected the word belongingness to this concept. “Belongingness, I really didn't appreciate that so much before. And I think even though you go through the motions, just having the words attached to it actually give it more meaning, which you then act that out more so-so that's what I found, actually, was really important. Just really trying to reflect back what it's like to be a student and how nice it would be if someone was really considerate of my needs and involved me as one of the team" [1] (p. 227).

Further to self-reflection of one's own practices, many participants commented that this had led them to reflect about their own work environment and colleagues [1].

\subsubsection{Development of Belongingness Strategies}

Participants commented on the attitudes of their colleagues, and the lack of understanding and appreciation that the clinical supervisor had a significant impact on students' future career choices. A number of participants commented that there were a number of nurses from their work place who would benefit from attending the day. It was viewed as a strategy that could be used to make others think about their practice and how they treat students. Some felt such days should be compulsory, with refreshers each year. "It should be compulsory to all staff who work with students. I can think of a number of people who should have been here...we must be aware not to eat our young” [1] (p. 199). There was a sense of frustration that staff had little to no appreciation about the impact that the clinical supervisor could have on a student, in terms of their decision to stay in the profession or in what area they would like to work. "Nursing staff need increased awareness of students and clinical placements. Some of us need to change our attitudes and approaches" [1] (p. 199). Participants commented about the need for staff to accept the role of teaching students, although there was a general feeling that sometimes it was best to keep these nurses that were uninterested away from students due to the impact that they could have. Participants noted this as an incentive to make a change in their workplace "I understand better how students feel when in my ward and I understand I have to break the barrier of some staffs' negative mindset” [1] (p. 192).

The next stage of awareness related to planning and making changes of practice.

\subsubsection{Development of Belongingness Strategies}

During the ACS participants were asked to consider strategies that could promote belongingness in their clinical setting. These ideas were often described in the participants' surveys, online reflections and interviews [1]. During an interview, one participant discussed how the concept of belongingness and an orientation program was important for student success, "I really took away the importance of a good solid orientation to students when they first arrive, that welcoming, how important that was. I guess I didn't really realise the impact of that until I sort of reflected on my own experiences of some of the poor welcomes that I got as a student. We tend to forget about that, I think, and that was a nice reminder. So if I got anything, that was my number one thing, I think, that I got out of the day... (also) greater preparation, and I guess looking at students more importantly than I possibly did in the past, but really plan for their arrival, obviously offer them a greater commitment than what I have done in the past” '[1] (p. 227).

Other participants suggested orientation manuals, and a web page for students on the hospital or their university site to provide further information. This information should be broad and relate to all aspects of the placement and health service, including parking, public transport details, nursing specialty care and patient diagnosis. 
Other participants described the need to include students on the rosters, this would allow for them to plan around allocated shifts given the number of competing factors that students now faced outside of their studies, but also to provide a sense that they were a member of the ward. Other ideas included taking more time to plan learning objectives and goals for each day "better at welcoming them and guiding them, asking what they want to achieve and involving other staff to attain their goals" [1] (p. 190).

Participants also shared experiences of engaging students in team meetings and the planning of patient care to "encourage confidence, belonging to a team, welcoming of new knowledge and experiences students can share with us" [1] (p. 191). Also taking the time to "Trust students with tasks where possible, be more active in reflections with students" [1] (p. 191). Other comments included the need to cater placements to each students learning journey, how they learn and how the ward can support them, "make a much bigger effort to make students comfortable, introduce them, write down their name on the board, provide more time for observation if required as not all students ready to jump in straight away, use more supportive and reflective sessions to ensure coping with the routine, break skills down more and give them parts to do they are confident with" [1] (p. 181).

The final stage related to participants sharing their opportunities to implement ideas and strategies for creating belongingness [1].

\subsubsection{Implementation of Belongingness Strategies}

Participants shared strategies that they had implemented since attending the ACS; these strategies are articulated in Figure 2 [1].

The ACS participants described how vital it was to pursue an environment of belongingness. A number of participants felt that this commenced with a suitable orientation to the health service and the clinical area [1]. "Making sure that they are introduced to everybody and understand what everybody's role is and feel free to approach them; and just take that extra time to introduce the cleaner or the OT or the doctor... sometimes there can be that oh we'll just introduce you to the nurses on the floor and the coordinator and maybe the manager and everybody else is a mysterious person wandering around... they're all important so it's important to know who they are, where they fit and to be made part of that team" [1] (p. 228).

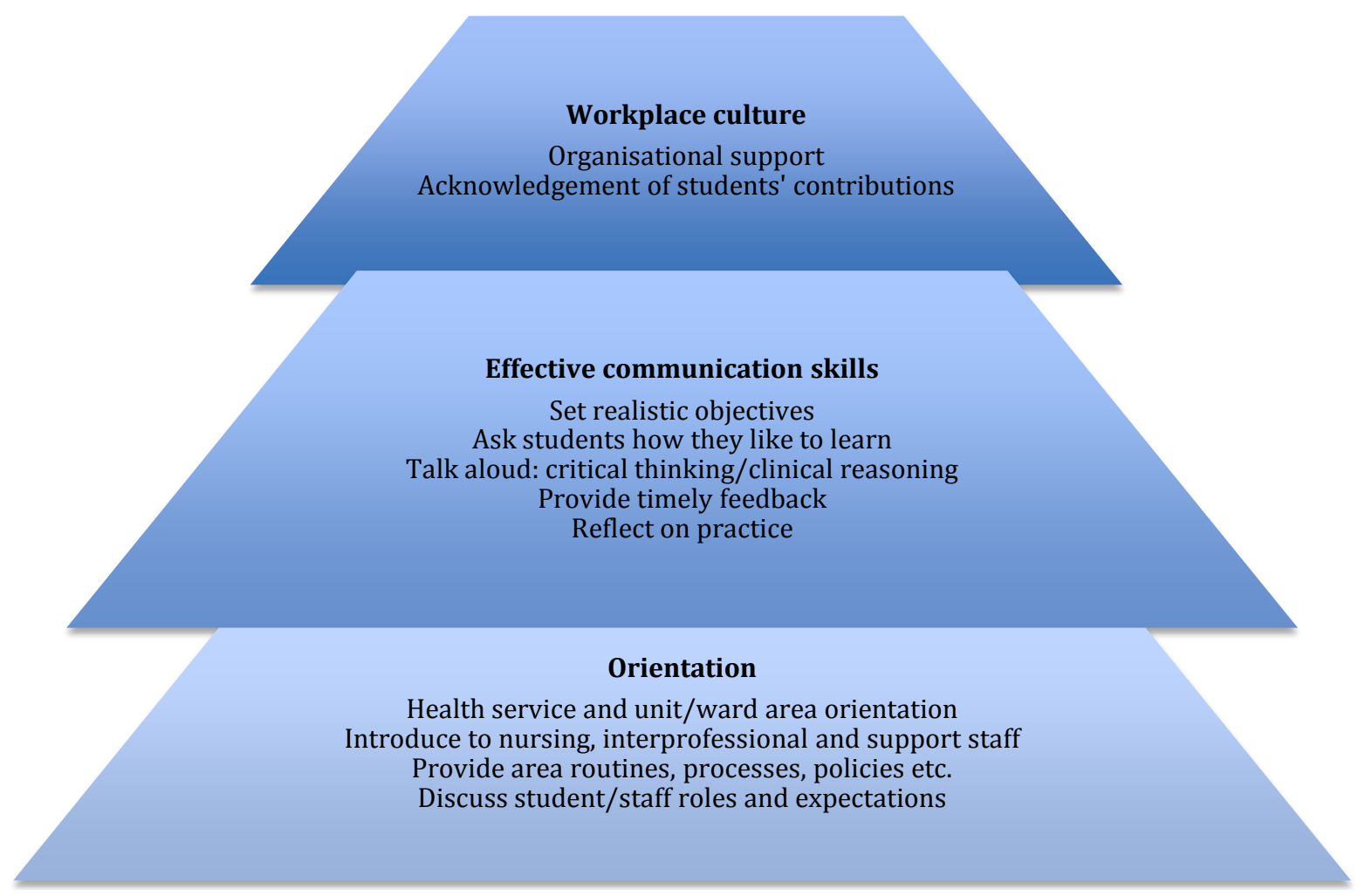

Figure 2. Strategies for belongingness by participants [1] (p. 236). 
The second stage for implementation related to effective communication skills. Participants felt that belongingness strategies could assist students to be proactive in their placement learning, by feeling safe and comfortable to ask questions and take the lead with patient care. Planning the day with the student would enable clear and achievable learning objectives that would place the student at ease to meet these agreed expectations. Participants felt that students needed to be encouraged and supported to take a more active role in the delivery of patient care, and to be trusted to plan care in conjunction with their supervisor, rather than simply be directed. By incorporating the student's opinions and ideas this also confirmed acceptance of their role and contribution to the team "it changed the way we mentored students in our work area and the feedback from other staff and students was extremely positive" [1] (p. 195).

The final strategy was linked to the wider health care team. It was felt that managers, executives and hospital policies needed to be more supportive of students, and welcome and acknowledge their contribution to the organization. The participants believed that the executive needed to provide support to ward staff so that they could provide an environment of belongingness. This in part could be demonstrated through the provision of ongoing education on the supervisor role, and the performance management of staff who refused to partake in supervision. Staff not being engaged was seen as an unfair distribution of workload, however this was often attached with feelings of guilt when placing a student with such a staff member. Staff expressed the need for training to be compulsory or strongly encouraged and supported by the hospital executive. Only with this acknowledgement of the role within the organization could the culture of the health service change to be welcoming, supportive and engaged in teaching and learning opportunities. It was expressed throughout the data that nurses required education about the role, and the principles of teaching, so that they could provide the best environment for students. It was felt this was not a natural skill set, even for those wanting to provide the best placement [1]. "I think it was an excellent initiative to have a proper study day, and it would be nice if it would be, the best word I can think of is compulsory, to get facility staff to take seriously the role of working with students and developing students, that we can't just pretend I'm a nurse, I've got a student, I know about nursing. We can do with it being quite a formal part of staff member's development that they come to study days such as that, that they've got a decent insight into what the role of the supervisor and the mentor is and how to deal with having a student" [1] (p. 222).

\section{Discussion}

Each year, thousands of student nurses in Western Australia attend clinical placements. The usefulness of these placements in part relies on the capacity of the nurses supervising the student. The role of the registered nurse is complex, and it cannot be assumed that nurses intuitively understand how to impart to students its components. The qualitative findings of this research indicate that staff desire greater support and development in the role of clinical supervision. Participants articulated that the ACS should be available to all staff, with many preferring mandatory attendance, as a tool to improve nurses understanding. In particular, the concept of belongingness was viewed as a simple and vitally needed strategy to welcome and support students. Ensuring students have a clear understanding of their role in the workplace and are supported to practice and ask questions, was seen to facilitate the application of theory to practice and the development of the student as a registered nurse [1].

Levett-Jones and Lathlean [5] included "Recommendations for Practice" to promote belongingness, however it would seem that these have not been widely implemented or evaluated. These recommendations were conceptualized as the "Accent to Competence conceptual framework", which the authors adapted from Maslow's Hierarchy of Needs [13]. The framework includes stages of achievement towards competence, describing the association between belongingness and student learning. Levett-Jones and Lathlean's [5] study described this journey towards competence as a transition between the stages of safety and security, belongingness, self-concept and learning. Recommendations for practice to achieve these stages were provided with the framework and includes strategies for education providers, health services and nurses [5].

\section{Recommendations}

Further research regarding this valuable concept of belongingness would be worthwhile to support implementation strategies; in particular, from the perspective of nursing staff, unit managers, nurse educators and clinical facilitators who could provide additional interpretation of its full potential and impact. Student numbers will continue to increase, placing an additional workload on nurses, this with an increasing clinical acuity of patients. Providing nurses with strategies for success are essential to ensure a positive learning environment [1]. 


\section{Conclusion}

The evaluation of the ACS has confirmed that participants perceived the concept of belongingness as fundamental to the success of a student clinical placement. Further research is required to develop clear strategies and guidelines to assist health service executives, managers and educators to implement effective belongingness strategies [1].

\section{Acknowledgements}

This research was supported by a grant from the Western Australian Nurses Memorial Charitable Trust for their support of this Ph.D.

The nurses who volunteered their time to partake in this research study.

\section{Declaration of Conflicting Interests}

The authors declare that they have no competing interests.

\section{References}

[1] Russell, K. (2013) The Art of Clinical Supervision Program for Registered Nurses PhD. The University of Notre Dame Australia. http://researchonline.nd.edu.au/theses/80/

[2] Health Workforce Australia (2011) Clinical Supervisor Support Program-Directions Paper. http://www.hwa.gov.au/sites/uploads/clinical-supervision-support-program-directions-paper-april-2011.pdf

[3] Levett-Jones, T. and Lathlean, J. (2008) Belongingness: A Prerequisite for Nursing Students’ Clinical Learning. Nurse Education in Practice, 8, 103-111. http://dx.doi.org/10.1016/j.nepr.2007.04.003

[4] Levett-Jones, T. and Lathlean, J. (2009) “Don’t Rock the Boat”: Nursing Students' Experiences of Conformity and Compliance. Nurse Education Today, 29, 342-349. http://dx.doi.org/10.1016/j.nedt.2008.10.009

[5] Levett-Jones, T. and Lathlean, J. (2008) The Ascent to Competence Conceptual Framework: An Outcome of a Study of Belongingness. Journal of Clinical Nursing, 18, 2870-2879. http://dx.doi.org/10.1111/j.1365-2702.2008.02593.x

[6] Levett-Jones, T., Lathlean, J., McMillian, M. and Higgins, I. (2007) Belongingness: A Montage of Nursing Students' Stories of Their Clinical Placement Experiences. Contemporary Nurse, 24, 162-174. http://dx.doi.org/10.5172/conu.2007.24.2.162

[7] Gasparini, A. (2010) Community and Territorial Belonging. Comparative Sociology, 9, 433-462. http://dx.doi.org/10.1163/156913210X12555713197097

[8] Christensen, A. (2009) Belonging and Unbelonging from an Intersectional Perspective. Gender Technology and Development, 13, 21-41. http://dx.doi.org/10.1177/097185240901300102

[9] May, V. (2011) Self, Belonging and Social Change. Sociology, 45, 363-378. http://dx.doi.org/10.1177/0038038511399624

[10] Cockshaw, W. and Shochet, I. (2010) The Link between Belongingness and Depressive Symptoms: An Exploration in the Workplace Interpersonal Context. Australian Psychologist, 45, 283-289. http://dx.doi.org/10.1080/00050061003752418

[11] Thau, S., Poortvliet, P. and Aquino, K. (2007) Self-Defeating Behaviours in Organizations: The Relationship between Thwarted Belonging and Interpersonal Work Behaviors. Journal of Applied Psychology, 92, 840-847. http://dx.doi.org/10.1037/0021-9010.92.3.840

[12] Baumeister, R. and Leary, M. (1995) The Need to Belong: Desire for Interpersonal Attachments as a Fundamental Human Motivation. Psychological Bulletin, 117, 497-529. http://dx.doi.org/10.1037/0033-2909.117.3.497

[13] Maslow, A. (1943) A Theory of Human Motivation. Psychological Review, 50, 370-396. http://dx.doi.org/10.1037/h0054346

[14] Brammer, J. (2008) RN as Gatekeeper: Gatekeeping as Monitoring and Supervision. Journal of Clinical Nursing, 17, 1868-1876. http://dx.doi.org/10.1111/j.1365-2702.2008.02376.x

[15] Webb, C. and Shakespeare, P. (2008) Judgments about Mentoring Relationships in Nurse Education. Nurse Education Today, 28, 563-571. http://dx.doi.org/10.1016/j.nedt.2007.09.006

[16] Vallant, S. and Neville, S. (2006) The Relationship between Student Nurse and Nurse Clinician: Impact on Student Learning. Nursing Praxis in New Zealand, 22, 23-33.

[17] Andrews, G. Brodie, D. Andrews, J., Wong, J. and Thomas, G. (2005) Placement Matters: Students' Clinical Expe- 
riences and Their Preferences for First Employers. International Nursing Review, 52,142-153. http://dx.doi.org/10.1111/j.1466-7657.2005.00262.x

[18] Landmark, B. Hansen, G., Bjones, I. and Bohler, A. (2003) Clinical Supervision-Factors Defined by Nurses as Influential upon the Development of Competence and Skills in Supervision. Journal of Clinical Nursing, 12, 834-841. http://dx.doi.org/10.1046/j.1365-2702.2003.00813.x

[19] Braun, V. and Clarke, V. (2006) Using Thematic Analysis in Psychology. Qualitative Research in Psychology, 3, 77101. http://dx.doi.org/10.1191/1478088706qp063oa 